\title{
Prevalence and genetic aspects of deaf mutism in Shanghai
}

\author{
DAN-NING HU*† WEI-QIN QIU*, BAO-TONG WU , LI-ZHOU FANG , FU

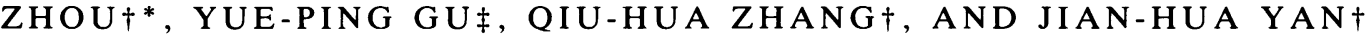 \\ From * the Department of Medical Genetics, Tiedao Medical College, Shanghai, China; the Department of \\ Population Genetics, Zhabei Eye Institute, Shanghai, China; and $¥$ the Department of Oto-Rhino-Laryn- \\ gology, Zhabei Central Hospital, Shanghai, China.
}

SUMMARY Two hundred and eighty-five cases of congenital deaf mutism were ascertained in a population of 483611 in Zhabei District in Shanghai. The prevalence was $0 \cdot 059 \%(1: 1697)$. Inherited cases accounted for $84.83 \%$ of all cases. The mode of inheritance was autosomal recessive with complete penetrance and heterogeneity (consisting of at least five different loci). The fitness was $77.63 \%$, the coefficient of selection was 0.2237 , the mutation rate was $1 \cdot 119 \times 10^{-4}$ mutation/gamete, and no heterozygote advantage was proven.

Deaf mutism is a major health problem. There are several reports on the genetics of deaf mutism, indicating autosomal recessive inheritance with heterogeneity, but the genetic aspects have not been completely elucidated. ${ }^{\text {-6 }}$ No such study has been carried out in China. This paper is concerned with the prevalence and genetic aspects of deaf mutism in Shanghai, based on complete ascertainment of deaf mutism in a district in Shanghai with a popluation of 483611 , and investigation of 285 pedigrees of deaf mute cases discovered in this study.

\section{Subjects and methods}

Zhabei District is one of the 12 districts in Shanghai City. A list of deaf mutes was obtained from the Zhabei Association of Deaf Mutism, and supplemented by the area's welfare officers, two schools for deaf children, and three factories for deaf mutes in Zhabei District. Since every case of deaf mutism is registered with the Zhabei Association of Deaf Mutism, is known to their area's welfare officers, and most of them are either in schools for deaf children or work in factories for deaf mutes, all of which were contacted, ascertainment could be assumed to be reasonably complete. Children under seven years old were excluded from this study, since the diagnosis is uncertain before that age.

Every deaf mute discovered in this study was visited by two of the authors. A detailed history re-

Received for publication 13 April 1987

Revised version accepted for publication 16 June 1987. garding the age of onset and knowledge of pathogenesis (infection, drugs, etc) was obtained. Each case was examined by an otologist. If there was any doubt about the existence of a deafness syndrome, a complete examination was performed by specialists to confirm or exclude the genetic syndrome. In cases of congenital deaf mutism (non-syndromic), a detailed family history was obtained from each proband, including the occurrence of deaf mutism in all relatives (first, second, and third degree) and careful inquiry was also made regarding the presence of parental consanguinity.

\section{Results}

PREVA LEN CE

A total of 763 deaf mutes was found in a population of 483611 in Zhabei District. Four hundred and seventy cases were diagnosed as acquired deaf mutism as hearing loss occurred in early infancy and a definite aetiological factor could be found in the history (including infection, antibiotics, other toxic drugs, etc). Seven cases were diagnosed as genetic deafness syndromes, including two cases of Usher's syndrome, two cases of Waardenburg's syndrome, two cases of deaf mutism associated with atresia of the external auditory meatus, and one case of Franceschetti's syndrome. One case was diagnosed as $\mathrm{X}$ linked recessive deaf mutism with late onset from study of the pedigree. Excluding these 478 cases, 285 cases remained as congenital nonsyndromic deaf mutism (CDM). The prevalence of CDM was $0.059 \%$ (1:1697), accounting for $37.5 \%$ of 
TABLE Probability value calculated by maximum likelihood method.

\begin{tabular}{|c|c|c|c|c|c|}
\hline \multirow{3}{*}{$\begin{array}{l}\text { Size of } \\
\text { sibships } \\
\text { (s) }\end{array}$} & \multirow{3}{*}{$\begin{array}{l}\text { No of } \\
\text { sibships } \\
\left(n_{s}\right)\end{array}$} & \multicolumn{3}{|c|}{ No of affected subjects } & \multirow{3}{*}{$\begin{array}{l}\text { Reciprocal } \\
\text { of variance } \\
p=0.225\end{array}$} \\
\hline & & \multirow[t]{2}{*}{ Observed } & \multicolumn{2}{|l|}{ Expected } & \\
\hline & & & $p=0.250$ & $p=0.225$ & \\
\hline 1 & 9 & 9 & 9 & 9 & $182 \cdot 000$ \\
\hline 2 & 50 & 59 & $57 \cdot 150$ & $56 \cdot 350$ & $342 \cdot 056$ \\
\hline 3 & 44 & 52 & $57 \cdot 068$ & 55.572 & 593.616 \\
\hline 4 & 48 & 80 & $70 \cdot 224$ & 67.584 & 593.616 \\
\hline 5 & 51 & 84 & 83.589 & 79.662 & $886 \cdot 380$ \\
\hline 6 & 33 & 47 & 60.225 & $56 \cdot 859$ & $751 \cdot 113$ \\
\hline 7 & 10 & 14 & $20 \cdot 200$ & $18 \cdot 930$ & $284 \cdot 580$ \\
\hline 8 & 2 & 2 & 4.446 & $4 \cdot 138$ & $68 \cdot 830$ \\
\hline 9 & 3 & 3 & $7 \cdot 289$ & 6.756 & $121 \cdot 734$ \\
\hline 10 & 2 & 3 & $5 \cdot 298$ & $4 \cdot 882$ & 93.792 \\
\hline Total & 252 & 353 & $374 \cdot 499$ & $359 \cdot 753$ & $3324 \cdot 101$ \\
\hline
\end{tabular}

all deaf mutes. Males and females were about equally affected.

\section{FAMILY HISTORIES \\ Parents}

In 260 pairs of parents of probands, both parents had CDM in eight pairs and both parents were unaffected in 252 pairs. In the 252 pairs of unaffected parents, 14 matings $(5 \cdot 6 \%)$ were between first cousins.

\section{Sibs}

The occurrence of CDM in the sibs was closely related to the status of the parents. In the eight families where both parents were affected, all the children were affected in six families and in the other two families some of the children were affected (three in eight children). In the families where both parents were unaffected, in 767 sibs of the probands, 101 were affected $(13 \cdot 1 \%)$. Since ascertainment in the present series is complete, the maximum likelihood method was used to estimate the corrected incidence in sibs. ${ }^{7}$ The $p$ value calculated was $0 \cdot 2208 \pm 0 \cdot 0174$, close to the expected figure for autosomal recessive inheritance, but somewhat lower (table).

\section{Spouses and offspring}

In 60 families where the proband married either an acquired deaf mute or a normal person and with at least one child, all children were normal out of 107 offspring. In 49 families where the proband married another person with CDM, and with at least one child, all children were affected in nine families (14 children) and all children were normal in the other 40 families (53 children).

\section{Discussion}

Stevenson and Cheesman ${ }^{1}$ published a detailed study on deaf mutism in Northern Ireland in 1978. Slatis ${ }^{2}$ and Chung $e t a l^{3}$ reanalysed these data and stated that most cases of hereditary deaf mutish were inherited as autosomal recessive with hetegeneity, a small proportion of deaf mutism bei inherited as autosomal dominant. Since then, other papers have been published regarding the p\&gvalence and genetic aspects of deaf mutism. ${ }^{4-N}$

\section{PREVALENCE}

The prevalence of CDM in the present series $1: 1697$, somewhat higher than the data reported Stevenson and Cheesman ${ }^{1}$ (1:3226).

MODE OF INHERITANCE

In the present series, most of the parents and chif ren of the probands were normal. The corrected cidence in sibs was $\mathbf{0 . 2 2 0 8}$ and the rate of parental consanguinity $(5.6 \%)$ was higher than for t⿱艹 $\mathrm{e}$ general population $(0.78 \%)$ in Shanghai. ${ }^{8}$ Combining all these facts, it would appear that the mode of inheritance of CDM is principally autosomal irecessive in the present series, though the occurrenge of some unaffected children in two families where both parents were affected suggests the existence - f some heterogeneity.

\section{PHENOCOPIES}

In the present series, in 14 consanguineous matings, the incidence of $C D M$ in the offspring was $0 . \%$, giving a good fit with autosomal recessive inheritance, but the non-consanguineous matings showed an excess of isolated cases. Formula 1 was used 90 estimate the proportion of sporadic cases. ${ }^{3}$

$$
Y=\frac{F_{f}-F_{i}}{F_{f}-\alpha}
$$

where $\mathrm{Y}$ is the proportion of simplex cases that 
sporadic. $F_{f}, F_{i}$, and $\alpha$ represent the inbreeding coefficient of the multiplex cases, simplex cases, and general population. $F_{f}$ and $F_{i}$ in the present series were 0.003906 and 0.003068 , respectively. The coefficient of inbreeding of the general population in Shanghai reported by the author in 1983 was $0.0004813 .{ }^{8}$ Using these data, we find $\mathrm{Y}=0.2447$.

There were 163 simplex cases in the present series, accounting for $61.98 \%$ of all cases of CDM, so the proportion of sporadic cases in all CDM was estimated as $15 \cdot 17 \%$, the remaining $84.83 \%$ cases can be postulated to be hereditary deaf mutism. Chung et $\mathrm{al}^{3}$ estimated that $9 \%$ of CDM in Northern Ireland were sporadic.

\section{PENETRANCE}

In the present series, the incidence of CDM in offspring of consanguineous matings was $0 \cdot 25$, equal to the expected figure in autosomal recessive inheritance, so penetrance may be complete. This result is consistent with the conclusions of Stevenson and Cheesman, ${ }^{1}$ Slatis, ${ }^{2}$ and Chung et al. ${ }^{3}$

\section{HETEROGENEITY}

Stevenson and Cheesman ${ }^{1}$ reported that in only five of 32 hereditary deaf by hereditary deaf matings were all children deaf. From this they concluded that there were probably six separate loci for recessive deaf mutism. Slatis ${ }^{2}$ and Chung et $_{\text {al }}{ }^{3}$ reanalysed this series and confirmed the notion of multiple recessive forms of deaf mutism.

In order to search for heterogeneity, we compared the gene frequency of CDM calculated from the prevalence and from parental consanguinity. The gene frequency of $\mathrm{CDM}$ was calculated from the frequency of parental consanguinity using formula 2 .

$$
q=\frac{C(1-K)}{16 K-15 C}
$$

where $\mathrm{q}$ is the gene frequency, $\mathrm{C}$ is the frequency of consanguineous unions in the general population, and $\mathrm{K}$ is their frequency in the patient population. The gene frequency $(q)$ thus calculated from parental consanguinity is 0.00940203 .

With the gene frequency calculated from the prevalence, the prevalence of hereditary $C D M$ is 0.0005 , and the gene frequency thus estimated is 0.02236 .

From the above data, we can conclude that the gene frequency of CDM as calculated from consanguinity is much less than that calculated from the disease prevalence, indicating heterogeneity.

We can estimate the number of loci contributing to a given recessive trait by Morton's formula. ${ }^{9}$

$$
\begin{gathered}
n=\frac{B^{2}}{A} \\
B=\frac{I(F-\alpha)}{\delta^{2}} \\
A=I-B \alpha
\end{gathered}
$$

where $n=$ number of loci, $I=$ prevalence in the population, $\mathrm{F}=$ inbreeding coefficient of the patient population, $\alpha=$ inbreeding coefficient of the general population, and $\delta^{2}=$ variance of inbreeding coefficient of the general population.

The prevalence of CDM in Shanghai is 0.0005 , the inbreeding coefficient is 0.0034375 , the inbreeding coefficient of the general population in Shanghai is 0.0004813 , and the variance of inbreeding coefficient of the general population in Shanghai is 0.0000287 .8

Using the above data and Morton's formula, the number of loci ( $n$ ) of CDM in Shanghai can be calculated as $5 \cdot 58$, so we can estimate that CDM in Shanghai may be caused by five or six different gene mutations.

Assuming that all CDM is caused by homozygosity for recessive genes, only nine of 49 marriages give evidence of homozygosity at the same locus. This figure also indicates that the most likely number of gene loci that cause CDM is five.

FITNESS, COEFFICIENT OF SELECTION, AND HETEROZYGOTE ADVANTAGE

The reproductive rates of the probands were compared with their normal sibs. The number of probands who reached reproductive age with at least one sib reaching reproductive age was 169 ; the total number of offspring of these 169 probands was 176 and the rate of reproduction of CDM in the present series was $1.0296\left(b_{1}\right)$. These 169 probands had 472 normal sibs who had reached reproductive age; the total number of offspring of these 472 sibs was 626 and the rate of reproduction was $1.3263\left(b_{2}\right)$. The fitness can be estimated from formula 3 .

$$
f=b_{1} / b_{2}
$$

where $f$ is the fitness and $b_{1}$ and $b_{2}$ represent the rate of reproduction of probands and their normal sibs. Fitness of CDM calculated from the present series was $0 \cdot 7763$.

The coefficient of selection (s) can be estimated by formula $4 .^{7}$

$$
\mathrm{s}=1-\mathrm{f}
$$

The coefficient of selection in the present series thus 
calculated is $\mathbf{0} \cdot 2237$. There is no reason why CDM should affect life span or fertility, so the low rate of reproduction may represent social factors.

The heterozygote advantage can be calculated with formula 5 .

$$
\mathrm{s}_{1}=\frac{\mathrm{q} \mathrm{s}_{2}}{1-\mathrm{q}}
$$

where $s_{1}$ is the coefficient of heterozygote advantage, $s_{2}$ is the coefficient of the abnormal homozygote, and $q$ is the gene frequency. $S_{1}$ calculated from the present series is 0.005116 , indicating negligible heterozygote advantage in CDM. This result is consistent with the results of Chung et al. ${ }^{3}$

MUTATION RATE

The mutation rate of a given autosomal recessive disease can be estimated indirectly with formula $6 .{ }^{7}$

$$
\mu=\mathrm{I}(1-\mathrm{f})
$$

where $\mu$ is the mutation rate, $I$ is the prevalence, and $f$ is the fitness.

The mutation rate calculated from the present series is $1.119 \times 10^{-4}$ mutation/gamete. The mutation rates estimated by Chung $e t \mathrm{al}^{3}$ from Northern Ireland and Denmark were $3.9 \times 10^{-4}$ and $2.8 \times 10^{-4}$ respectively.

THE POSSIBILITY OF AUTOSOMAL DOMINANT IN HER IT A N CE

Stevenson and Cheesman ${ }^{1}$ concluded that all cases of hereditary deaf mutism were inherited as autosomal recessive, but some authors have stated that a small proportion of hereditary deaf mutism might be inherited as autosomal dominant. ${ }^{2-4}$ In the present series, no parent-child inheritance was encountered in matings between congenital deaf mutes with $\overrightarrow{\mathbb{F}^{*}}$ normal subject or one with acquired deaf mutismOf nine pairs of probands married to another con genital deaf mute, all of the offspring were affectect In eight pairs of parents of probands who were both affected, all of the offspring were affected in sie pairs and normal offspring only occurred in twळ pairs. The two pairs with normal offspring mas indicate autosomal dominant inheritance, but thesecases can also be explained by autosomal recessive inheritance if a homozygote married a heterozygote If this is accepted, and the latter seems more likely these results indicate that all CDM in Shanghai can be explained by autosomal recessive inheritance:

\section{References}

' Stevenson AC, Cheesman EA. Hereditary deaf mutism, witb particular reference to Northern Ireland. Ann Hum Genet 1956;20:177-207.

2 Slatis HM. Comments on the inheritance of deaf mutism if Northern Ireland. Ann Hum Genet 1958;22:153-7.

${ }^{3}$ Chung CS, Robison OW, Morton NE. A note on deaf mutismo Ann Hum Genet 1959;23:357-66.

${ }^{4}$ Fraser GR. The cause of profound deafness in childhood. Batimore: Johns Hopkins University Press, 1976.

${ }^{5}$ Konigsmark BW, Gorlin RJ. Genetic and metabolic deafness.. Philadelphia: Saunders, 1976.

${ }^{6}$ Brown KS. The genetics of childhood deafness. In: McConnell Fo ed. Deafness in childhood. Nashville: Vanderbilt Universit Press, 1967: 177.

7 Emery AEH. Methodology in medical genetics, Edinburgho Churchill Livingstone, 1976: 21-34, 37-48.

${ }^{8}$ Hu DN, Chen VX, Cai VR. Frequency and genetic effect of cor尺 sanguineous matings. Hereditas 1983;5:27-8

${ }^{9}$ Morton NE. The mutational load due to detrimental genes i man. Am J Hum Genet 1960;12:348-64.

Correspondence and requests for reprints to $\mathrm{Dr} D$ Hu, Room 402, 490 Shan Xi Nan Road, Shangha臽 China. 